\title{
Neonatal euthanasia: moral considerations and criminal liability
}

Mark Sklansky University of California, San Diego, California, USA

\begin{abstract}
Despite tremendous advances in medical care for critically ill newborn infants, caregivers in neonatal intensive care units still struggle with how to approach those patients whose prognoses appear to be the most grim, and whose treatments appear to be the most futile. Although the practice of passive neonatal euthanasia, from a moral perspective, has been widely (albeit quietly) condoned, those clinicians and families involved in such cases may still be found legally guilty of child abuse or even manslaughter. Passive neonatal euthanasia remains both a moral dilemma and a legal ambiguity. Even the definition of passive euthanasia remains unclear. This manuscript reviews the basic moral and legal considerations raised by the current practice of neonatal euthanasia, and examines the formal position statements of the American Medical Association and the American Academy of Pediatrics. The paper concludes by emphasising the need, at least in the United States, to clarify the legal status of this relatively common medical practice.

(Fournal of Medical Ethics 2001;27:5-11)
\end{abstract}

Keywords: Euthanasia; neonatal intensive care; defective newborns

Despite tremendous technological advances in medical care, caregivers in neonatal intensive care units still struggle with how to approach those patients whose prognoses appear to be the most grim. Occasionally, such patients may prompt parents and medical caregivers to ask the question, are we doing the right thing in prolonging this patient's life? Caregivers who manage critically ill newborns should understand the complex moral principles and potential criminal liability associated with their practice of passive neonatal euthanasia.

Following a brief introduction to the concept of euthanasia, this paper reviews basic moral principles, and then discusses four questions which speak to the primary moral dilemmas raised by the question of neonatal euthanasia. Next, the formal positions of the American Medical Association (AMA) and the American Academy of Pediatrics (AAP) are presented. Finally, the legal background and current legal status of neonatal euthanasia in the United States is explored, concluding with a recommendation for society to clarify the legal status of neonatal euthanasia.

\section{Background}

Part of the complexity of euthanasia arises because the term "euthanasia" means different things to different people. Euthanasia derives from the Greek for good ("eu") and death ("thanatos"). In recent times, the term has come to refer to the action, motivated by mercy, and in an effort to avoid prolonged and futile suffering, of deliberately bringing about the death of another individual in as painless a way as possible. Active euthanasia (also known as "mercy killing") refers to that class of euthanasia wherein the death is directly and actively caused by another person. Passive euthanasia refers to those cases of euthanasia wherein death occurs because of absence of an intervention that would have prolonged life; passive euthanasia usually refers to withholding or withdrawing life-supporting therapy. The distinction between active and passive euthanasia sometimes blurs, as in the act of removing a patient from the ventilator. Even when this distinction is clear, however, its moral relevance may not be.

Euthanasia may be further classified in terms of the degree of expressed consent. Voluntary euthanasia refers to euthanasia expressly requested by the patient. Involuntary euthanasia refers to euthanasia against the patient's will, motivated paternalistically to promote the best interests of the patient. In the neonatal intensive care unit, patients cannot express their desires for or against dying. One may argue that infants cannot even have such desires. Appropriately, the term non-voluntary euthanasia has been proposed to describe euthanasia without a patient's will (or expressed will), as would occur with any instance of neonatal euthanasia.

\section{Moral considerations}

A. MORAL PRINCIPLES

The morality of euthanasia for actual cases of defective newborn infants is seldom clear. Commonly, different moral considerations may support opposing courses of action. Some understanding of sometimes competing moral principles-autonomy, beneficence, non-maleficence, and justice ${ }^{1}-$ can help the clinician constructively approach important moral questions related to the question of neonatal euthanasia.

The notion of autonomy confers on "competent" individuals the right to refuse medical treatment on any grounds, even when such refusal is contrary to the individual's best interests. Because neonates 
lack the ability to make decisions about their futures, the conventional meaning of autonomy has little moral bearing on the treatment of defective newborn infants.

The principle of beneficence ascribes moral virtue to actions which aim to benefit another person. Beneficent actions aim to maximise someone else's best interests. Because neonates are unable to form opinions regarding what would maximise their short and long term best interests, those individuals caring for newborns may offer "substituted judgments". However, whether the principle of beneficence supports prolonging the life of a critically defective newborn may not always be clear.

The flip-side of beneficence, non-maleficence, suggests that the morally correct action is that which does not promote harm, pain or suffering: "primum non nocere". In medicine, where modern technology offers sophisticated treatments to prolong life, the potential to prolong suffering is high. Treatments which prolong suffering must be carefully considered and justified. The closely related notion of paternalism characterises those actions, motivated by beneficence and nonmaleficence, which aim to maximise the best interests of one individual without or even against that person's expressed consent. Outside of neonatal and paediatric medicine, paternalistic inclinations may conflict with the principle of autonomy. In neonatal medicine, however, the principle of autonomy naturally takes a backseat to the moral imperatives of beneficence and non-maleficence.

The principle of justice speaks of fairness, rights and duties. In terms of neonatal medicine, and the question of neonatal euthanasia, justice dictates that any given neonate should be treated like all other "medically similar" neonates. The principle of justice demands the protection of certain rights, even when doing so may conflict with the principle of beneficence: "an act which is 'more humane' than its alternative may be morally objectionable because it infringes rights". ${ }^{2}$ This idea may be particularly clinically relevant for those involved with neonatal intensive care who recognise a neonate's right to life.

\section{B. Moral Questions}

In real life, complex cases of critically ill babies create moral dilemmas because the principles of autonomy, beneficence, non-maleficence and justice may support opposing courses of action Should one principle take precedence over another? Bringing clinical relevance to these moral principles, the following discussion approaches four basic moral questions implicit to the concept of neonatal euthanasia.

\section{Can euthanasia ever be morally justified?}

The first question to address is whether the deliberate and merciful bringing about (or allowing to come about) of a relatively peaceful death can ever be morally justified. Those who say no commonly suggest that human life is sacred and not to be taken under any circumstances. This position may be religiously based, or may be based on the conviction that the sanctity-of-life principle represents the foundation of social order and morality.

Another argument against neonatal euthanasia suggests that although certain cases of euthanasia may be morally correct, the practice itself should be forbidden because of the potential for mistakes: "where there's life, there's hope". In other words, for any given infant, the diagnosis or prognosis may be wrong, or a new effective treatment may soon be developed. In such cases, prolonging life and foregoing euthanasia might result in greater longevity or happiness than initially expected.

The "slippery slope" argument emphasises that although some instances of neonatal euthanasia may be morally justifiable, formally to condone the practice of euthanasia would likely lead to abuse. If society initially allows selected cases of neonatal euthanasia, the tendency may be for the practice to expand from non-voluntary to involuntary euthanasia: "the legal machinery initially designed to kill those who are a nuisance to themselves may some day engulf those who are a nuisance to others". ${ }^{3}$ The slippery slope works by "domesticating one idea and thus making its nearest neighbour down the slope seem less extreme and unthinkable". An additional slippery slope concern is that permitting some forms of neonatal euthanasia may lead directly to a decline in society's moral fabric, with a general reduction in respect for human life. ${ }^{5}$

\section{What forms of euthanasia are justifiable?}

Many caregivers of critically ill infants believe that some instances of neonatal euthanasia are morally justified and represent the "right thing to do" despite the preceding arguments against euthanasia (sanctity of life, possibility of wrong diagnosis/ prognosis, and slippery slopes). For those who believe that neonatal euthanasia may be morally justified in selected cases, the next question to address is what forms of euthanasia may be morally justified-active, passive or both?

Common medical practice in North America ${ }^{6}$ and Europe ${ }^{7-9}$ condones passive euthanasia, in certain cases, but never active euthanasia. Two ethical issues should be considered. First, is there an intrinsic moral distinction between killing and letting die? Second, if there is no moral distinction, are there still moral reasons to justify one form of euthanasia but not the other?

Despite common medical practice and most caregivers' perception of the law, many believe that there is no intrinsic moral distinction between killing and letting die. In some instances, such as removing a patient from a ventilator or discontinuing intravenous fluids, the distinction between killing and letting die blurs. But even when the distinction is clear, the moral relevance of this distinction may not be:

"If a doctor deliberately let a patient die who was suffering from a routinely curable illness, the doctor would certainly be to blame for what he had done, just as he would be to blame if he had needlessly 
killed the patient ... it would be no defense at all for him to insist that he didn't do 'anything'. He would have done something very serious indeed, for he let his patient die." ${ }^{\prime 10}$

Those who believe that a moral distinction does exist usually conclude that killing is less morally acceptable than letting die. The complexities of real life, however, generate instances which challenge such a position. In some cases, for instance, the principle of beneficence may even support active euthanasia over passive euthanasia:

“.... we would never consider allowing a horse or dog to die in agony if it could be killed painlessly. Once we see that the case of a dying horse is really quite parallel to the case of a dying infant, we may be more ready to drop the distinction between killing and letting die in the case of the infant too."11

Two independent arguments suggest, however, a moral superiority of letting die over killing. Even though killing and letting die may be morally equivalent, in and of themselves, and even though in some instances killing may be more humane than letting die, the consequences of allowing a practice of passive but not active euthanasia may promote the greatest good:

“... the disutility of introducing legitimate killing into one's moral code (in the form of active euthanasia rules) may, in the long run, outweigh the utility of doing so, as a result of the eroding effect such a relaxation would have on rules in the code which demand respect for human life... rules permitting killing could lead to a general reduction of respect for human life..." ${ }^{\prime 12}$

Furthermore, a policy allowing passive but not active euthanasia would save the lives of a real group of patients (wrongfully diagnosed as hopeless, but who would survive only if treatment is continued) who would be wrongfully killed were both passive and active euthanasia to be allowed. ${ }^{12}$

\section{Which patients should be considered for neonatal euthanasia?}

If one considers euthanasia-either active or passive - to be morally acceptable in certain situations, the next question to address is under what situations? What criteria should be used to determine whether euthanasia for a given patient is the morally correct thing to do? This section will discuss some of the most commonly proposed moral criteria, each independent of the active versus passive distinction: personhood, costs of treatment, quality of life, and best interests.

Personhood: Those who oppose euthanasia under any circumstance may invoke the notion of the sanctity of human life, which invests every human being with a right to life. A parallel but critically distinct mode of thought suggests that an individual's right to life derives not from being the biological product of two human beings, but rather from possessing those characteristics which represent the moral essence of being a person. This distinction contrasts the biological, genetic concept of a "human being" with the moral make-up of a "person" ${ }^{13}$ For example, Michael Tooley has suggested that a person, in the moral sense, must be able to envisage a future for itself and have desires about its own future states. ${ }^{14}$ This moral notion of personhood generates problematic clinical implications which contradict some of society's deepest moral intuitions; if an individual's right to life derives from "personhood," then no neonate would be entitled to such a right to life.

An alternative conception of personhood attributes to human newborns personhood in the social sense, which avoids this conflict with society's considered moral judgments. This social sense of personhood, largely a utilitarian construct, helps to preserve society's interest in protecting its persons in the strict sense:

“... it is difficult to determine specifically when in human ontogeny persons strictly emerge. Socializing infants into the role person draws the line conservatively. Humans do not become persons strictly until sometime after birth... . Unlike persons strictly, who are bearers of both rights and duties, persons in the social sense have rights but no duties. That is, they are not morally responsible agents, but are treated with respect (ie, rights are imputed to them) in order to establish a practice of considerable utility to moral agents: a society where kind treatment of the infirm and weak is an established practice... . The social sense of a person is a way of treating certain instances of human life in order to secure the life of persons strictly." ${ }^{15}$

In terms of neonatal euthanasia, personhood in the strict sense denies to all newborn infants a right to life, whereas personhood in the social sense entitles all newborn infants to a right to life. It would appear that personhood, in either sense, fails as a moral criterion in the context of neonatal euthanasia. However, personhood in the strict sense may be an acceptable criterion if one allows, at least in this context, the consideration of whether a particular infant (a person in the social sense) has the potential to develop into a person in the strict sense.

Costs of treatment: A second possible moral consideration, in addition to the potential for personhood in the strict sense, is the cost of treatment in terms of financial resources. We live in a world where resources for medical care are limited, and resources devoted to one patient, at some level, may mean resources unavailable for another. Considerations of distributive justice suggest that treatment costs should enter the decision, at some level, whether to provide ongoing medical treatment for critically ill newborns. However, applying such public policy questions at the bedside may be inappropriate.

Quality of life: An infant's expected quality of life intuitively seems to be relevant in deciding whether to continue treatment. For patients who are 
expected to have a life full of suffering and devoid of pleasure, providing medical treatment to prolong life seems not only unnecessary but possibly even cruel and wrong. At the same time, many children and adults live lives of suboptimal "quality", yet still would prefer living to the alternative. For this reason, many have suggested that quality of life not be considered an independent morally relevant criterion. Instead, quality of life may be considered as one criterion in the context of determining what is in the patient's best interests. Importantly, a projected quality-of-life determination can be no more accurate or certain than the medical assessment of a patient's prognosis.

Best interests: Probably the most widely accepted criterion for determining the morality of euthanasia for any given newborn is the answer to the question, what is in the infant's best interests? Although the answer may not be straightforward, the question itself helps caregivers put self interests and biases aside in an effort to do the right thing for the patient. In this context, once one has determined the infant to be a potential person in the strict sense, quality of life, familial and social resources may become relevant, but only insofar as they help predict what treatment choice would ultimately be in the patient's best interests.

\section{Who should decide?}

For those who feel that neonatal euthanasia may be morally justified under certain situations, an additional challenging question remains: who should decide for any given infant. Decisions to withdraw support for terminally ill newborns commonly are made jointly by parents and physicians. When disagreements occur, consultations from a hospital ethics committee may be obtained. When disagreements persist, the court system may be asked to make a final ruling. From a moral perspective, life-and-death decisions for defective newborn infants should be made by that individual (or set of individuals) most likely to make the choice that best promotes the best interests of the infant. This section will consider the relative merits, in this regard, of parents, physicians, and infant care review committees.

Parents typically represent the most appropriate decision makers in life-and-death decisions for their children. Because of the love parents typically have for their own children, parents may be expected naturally to act in the best interests of their children. For this and other reasons, society grants to parents significant discretionary decision making authority (in the form of rights and duties) for the health care of their children.

However, parents may not always act in the best interests of their children. Parents may not be able to act in their child's best interests because the stress of the birth of a defective child may distort their judgment. ${ }^{16}$ Additionally, long term care of a severely defective infant and child can place tremendous emotional, social and financial pressures on any family; parents may consider the anticipated effects of their decision on the rest of the family.

Physicians represent the next most appropriate decision makers for defective newborn infants. Unlike parents, who generally have only minimal medical knowledge and insight, physicians have a unique perspective on prognosis and expected quality of life. Moreover, physicians may be able to provide a level of objectivity and consistency which emotionally invested and drained parents cannot.

Nevertheless, physicians as decision makers fall short in important ways. Physicians may be partial towards non-treatment because of a bias towards normalcy. In recent times, this bias may not be entirely selfless; health insurance organisations, many involved in decision making, may "reward physicians who keep their patients away from expensive care". ${ }^{17}$ Moreover, the ability of physicians to make decisions which promote the newborn's best interests may be hindered by multiple personal and professional stresses. ${ }^{18}$

Because of the limitations faced by both parents and physicians consistently to promote the best interests of defective newborn infants, the Infant Care Review Committee (ICRC) has been proposed. Initially, in 1984, the ICRC was promoted by the Department of Health and Human Services to provide consultations, not decisions. The ICRC was conceived to include "a practicing physician, a practicing nurse, a hospital administrator, a social worker, a representative of a disabled group, a lay community member, and a member of the facility's organized medical staff as chair" ${ }^{17}$ As of $1998,84 \%$ of large American hospitals had enacted ethics committees to provide consultations, not definitive rulings. ${ }^{19}$

The advantages of an ICRC (as a decision making body) include its potential to provide a relatively independent, unemotional, and well-educated recommendation which is likely to be made in an effort to promote the best interests of the newborn infant. However, life-and-death decisions regarding critically ill babies frequently need to be made quickly, something which decisions by committee commonly cannot provide. Over time, committees may suffer from the tendency to become dominated by a single individual or point of view. Furthermore, placing decision making authority into the hands of a committee would dramatically limit parental and physician autonomy and discretion.

\section{Formal Position STATEMENTS}

In 1997, the AMA addressed the issue of neonatal euthanasia in its formal position statement, Code of Medical Ethics. ${ }^{20}$ Although euthanasia may be either active or passive, the AMA's definition of "euthanasia" represents the more commonly accepted definition of "active euthanasia". The AMA position supports some cases of passive neonatal euthanasia, but condemns all cases of active neonatal euthanasia on utilitarian grounds. ${ }^{21}$ The AMA states that life-sustaining medical treatment, including antibiotics and artificial nutrition and hydration, should be foregone for certain critically 
ill infants, utilising the best interests standard. The AMA then delineates what it considers to be morally relevant criteria in determining an infant's best interests. Note that the inclusion of the quality-oflife criterion opens the door to considering social circumstances, which may not otherwise have been allowed into the decision making process:

"Factors that should be weighted are (1) the chance that therapy will succeed, (2) the risks involved with treatment and nontreatment, (3) the degree to which the therapy, if successful, will extend life, (4) the pain and discomfort associated with the therapy, and (5) the anticipated quality of life for the newborn with and without treatment."22

Occasionally physicians may perceive that the parents have made a choice that is not in the patient's best interests. In such cases, the AMA recommends referral to an ethics committee, which would report to public authorities cases in which the parents do not appear to be acting in the best interests of their newborn infants. ${ }^{23}$

In 1996, The American Academy of Pediatrics (AAP) issued a similar formal position statement. ${ }^{24}$ The AAP condones certain cases of passive neonatal euthanasia: "Physicians should recommend the provision or forgoing of critical care services based on the projected benefits and burdens of treatment". ${ }^{25}$ While the AAP leaves undefined the criteria for patient selection, the AAP does not consider macroeconomic issues of distributive justice to be relevant to individual cases: “... resource allocation (rationing) decisions about which children should receive intensive care resources should be made clear and explicit in public policy, rather than be made at the bedside" ${ }^{26}$

Formal position statements from Europe similarly condone allowing certain infants to die. ${ }^{7-9}$ Nevertheless, neither American nor European statements consider such actions to represent forms of passive neonatal euthanasia. Thus, semantic confusion complicates moral ambiguity on both sides of the Atlantic.

\section{Legal considerations}

\section{A. Child Abuse Prevention and Treatment} ACT

In 1984, the Department of Health and Human Services (DHHS) issued a series of amendments under the Child Abuse Prevention and Treatment Act. The amendments attempted to protect disabled infants with life-threatening conditions from being denied medically indicated treatment. While "child abuse" was defined to include "nontreatment of a child by a person who is responsible for that child's welfare", "withholding of medically indicated treatment" was defined to exclude cases in which:

A) the infant is chronically and irreversibly comatose,

B) the provision of such treatment would

i) merely prolong dying ii) not be effective in ameliorating or correcting all of the infant's life-threatening conditions, or

iii) otherwise be futile in terms of the survival of the infant, or

C) the provision of such treatment would be virtually futile in terms of the survival of the infant and the treatment itself under such a circumstance would be inhumane. ${ }^{27}$

The Child Abuse amendments of 1984 may be criticised on several grounds. First, while these statutes define instances of medical neglect of disabled infants, they do not make such behaviour criminal. Instead, the statutes work by requiring each state, if it wants to continue to receive federal funding for its child protective services programmes, to implement programmes which aim to identify and protect infants from being denied medically indicated treatment. $^{28}$ Second, the amendments include ambiguous terms such as "futile", "appropriate" and "inhumane". Third, they diminish the rights of parents and physicians to make life-and-death decisions for critically ill infants in their care. Finally, although the amendments purport to reject quality of life as a relevant criterion for decision making, the exceptions are based upon quality-of-life judgments. ${ }^{2}$

\section{B. CRIMINAL Liability}

While medical professionals involved in the care of critically ill infants recognise active euthanasia to be illegal, many believe that, in certain instances, passive neonatal euthanasia may be legal. The Child Abuse amendments of 1984 describe a class of defective infants for whom foregoing lifesupporting treatment is not considered to be medical neglect. Even in these cases, however, parents and medical personnel may risk criminal prosecution. The California Penal Code, for instance, suggests that anyone who wilfully fails to provide care that he/she has a duty to provide, knowing that such failure will result in death, may be found guilty of murder or manslaughter. The legal limits to such duties, for both parents and medical personnel, have not been clearly defined.

Regardless of the circumstances, parents who choose to forego life-sustaining medical treatment for their newborn infants may face prosecution for manslaughter or murder. John Robertson, Professor of Law at the University of Texas, has written extensively in this area of medical law:

"In the case of a defective infant the withholding of essential care would appear to present a possible case of homicide by omission on the part of parents, physicians, and nurses, with the degree of homicide depending on the extent of premeditation. Following a live birth, the law generally presumes that personhood exists and that there is entitlement to the usual legal protections, whatever the specific physical and mental characteristics of the infant may be. Every state imposes on parents a legal duty to provide necessary medical assistance to a helpless minor child. If they withhold such care and 
the child dies, they may be prosecuted for manslaughter or murder..."

Likewise, physicians ${ }^{31}$ and nurses ${ }^{32}$ may face criminal liability for participating in a case of passive neonatal euthanasia, even when all parties, including the parents, are in agreement.

Those involved with foregoing life-sustaining medical treatment for disabled infants may also be prosecuted for child abuse and neglect. According to the California Penal Code, "'neglect' means the negligent treatment or the maltreatment of a child by a person responsible for the child's welfare... The term includes both acts and omissions on the part of the responsible person". ${ }^{3}$

The practice of foregoing life-sustaining medical treatment for critically ill infants has become fairly widespread, despite potential criminal liability of the medical personnel and parents. Nevertheless, no such "criminal" has yet been successfully prosecuted. A marked difference exists between the law in the books, which appears to make passive neonatal euthanasia illegal, and the law in action, which does not punish it. ${ }^{34}$ This disparity exists, in part, because such cases rarely come to the attention of legal authorities. ${ }^{35}$ On a deeper level, the lack of prosecutions may reflect a judgment among district attorneys that such actions do not deserve to be prosecuted:

“... prosecutors may respect parental autonomy, find themselves in agreement with the parents position, be reluctant to press criminal charges because such prosecution might prove politically unpopular, be hesitant to challenge the discretion of the physicians in the case, believe that the presiding judge in a court hearing would agree with the decision made in the NICU, be concerned about the emotional stress on all parties in the case, feel that a criminal procedure would be disproportionate for the circumstances, or simply conclude that they lack sufficient personnel to do the amount of legal work required to get a conviction in the case. ${ }^{36}$

\section{Conclusion}

Confusion regarding the definition of neonatal euthanasia pales in comparison with euthanasia's moral and legal complexity. The law, perhaps more so than morality, speaks clearly about active euthanasia. However, the moral and legal status of passive neonatal euthanasia, (ie, withholding/ withdrawing treatment from critically ill newborn infants) remains ambiguous. Parents and physicians have legal duties to provide medical care for defective infants, but the limits to these duties have not been well defined. Parents, physicians and nurses who participate in foregoing life-sustaining medical treatment for critically ill infants may be found guilty of child neglect, manslaughter or murder. Thus, the formal position statements of the AMA and the AAP (as well as several from Europe) appear to condone a practice for which persons may be found criminally liable in the United States, and probably in parts of Europe.
Because the law should reflect, not define, our most considered moral judgments, the best possible legal solution should include a process for decision making which minimises the risk of abuses and mistakes. ${ }^{37}$ The specific criteria for the "best interests of the newborn" should not and cannot be enumerated by the law. But if we as a society believe that certain instances of passive neonatal euthanasia should be allowed, with some discretion left to parents and physicians, the law should make this clear. The legal status of the widespread practice of passive neonatal euthanasia needs to be reviewed and clarified, at least in the United States, and perhaps on both sides of the Atlantic.

\section{Acknowledgment}

The author thanks David Sklansky, Professor of Law, University of California, Los Angeles for sharing his perspective on the legal status of neonatal euthanasia.

Mark Sklansky, MD, FAAP, FACC, is Associate Professor of Pediatrics at the University of California, San Diego, California, USA.

\section{References}

1 Beauchamp T, Childress J. Principles of biomedical ethics. New York: Oxford University Press, 1979.

2 Foot P. Euthanasia. In: Ladd J, ed. Ethical issues relating to life and death. New York: Oxford University Press, 1979: 30.

3 Kamisar Y. Euthanasia legislation: some nonreligious objections. In: Beauchamp T, Perlin S, eds. Ethical issues in death and dying. New Jersey: Prentice-Hall, 1978: 221.

4 Schneider C. Rights discourse and neonatal euthanasia. California Law Review 1988;76:168.

See reference 1: 113 .

6 Wall S, Partidge J. Death in the intensive care nursery: physiWian practice of withdrawing and withholding life support. Pedician practice of withd
atrics 1997;99:64-70

atrics 1997;99:64-70.

7 Royal College of Paediatrics and Child Health. Withholding or withdrawing life saving treatment in children. A framework for practice. London: RCPCH, 1997

8 British Medical Association. Withholding and withdrawing life-prolonging medical treatment. London: BMJ Books, 1999.

9 McHaffie H, Cuttini M, Brolz-Voit G, Randag L, Mousty R, Duguet A, et al. Withholding/withdrawing treatment from neonates: legislation and official guidelines across Europe. fournal of Medical Ethics 1999;25:440-6.

10 Rachels J. Active and passive euthanasia. New England fournal of Medicine 1975;292:78-80.

11 Singer P. Unsanctifying human life. In: Ladd J, ed. Ethical issues relating to life and death. New York: Oxford University Press, 1979: 53 .

12 Beauchamp T. A reply to Rachels on active and passive euthanasia. In: Beauchamp T, Perlin S, eds. Ethical issues in death and nasia. In: Beauchamp T, Perlin S, eds. Ethical

13 Tooley $M$. Decisions to terminate life and the concept of person. In: Ladd J, ed. Ethical issues relating to life and death. New York: Oxford University Press, 1979: 64-5.

14 See reference 13: 91 .

15 Engelhardt Jr, HT. Medicine and the concept of person. In: Beauchamp T, Perlin S, eds. Ethical issues in death and dying. New Jersey: Prentice-Hall, 1978: 277-8.

16 Knepper K. Withholding medical treatment from infants: when is it child neglect? University of Louisville fournal of Family Law 1994;33:31

17 Shapiro R, Barthel R. Infant care review committees: an effective approach to the baby Doe dilemma? The Hastings Law fournal 1986;37:848.

18 Weir R. Selective nontreatment of handicapped newborns: moral dilemmas in neonatal medicine. New York: Oxford University Press, 1984: 257.

19 Wilson R. Hospital ethics committees as the forum of last resort: an idea whose time has not come. North Carolina Law Review 1998;76:357. 
20 American Medical Association: Council on Ethical and Judicia Affairs. Code of medical ethics. Chicago: AMA, 1996.

21 See reference 20:55

22 See reference 20: $3 \mathrm{a}$.

24 American Academy of Pediatrics. Ethics and the care of critically ill infants and children. Pediatrics 1996;98:149-52.

25 See reference 24: 151 .

26 See reference $24: 149$.

27 Child abuse prevention and treatment amendments of 1984

US code title 42 , section $5106 \mathrm{~g}$

28 See reference 17: 837
29 Anonymous. Neonatal treatment decisions. Harvard Law Review 1990;103:1602.

30 Robertson J, Fost N. Passive euthanasia of defective newborn infants: legal considerations. Fournal of Pediatrics 1976;88:884. 31 Robertson J. Involuntary euthanasia of defective newborns: a legal analysis. Stanford Law Review 1975;27:224.

32 See reference 30: 885

33 California Penal Code, section 11165.2.

34 See reference 29: 1591.

35 See reference $31: 244$.

36 See reference $18: 102$.

37 See reference 30: 888

\section{News and notes \\ Death without Suffering}

Death without Suffering, an Advanced European Bioethics course, will run from the 5 th to the 7 th of April, 2001 in Nijmegen, the Netherlands. Subjects will include: Death and suffering in Western culture; Death and suffering: ethical perspectives; Suffering and the ideal of painlessness; Palliative care and euthanasia, and Ethical issues in pain management in hospice care.
The conference will be in English. For more information please contact: N Steinkamp, MA, University Medical Centre, Nijmegen, Dept 232 Ethics, Philosophy and History of Medicine, PO Box 9101, $6500 \mathrm{HB}$ Nijmegen, the Netherlands. Telephone: ++31 24 3615320; fax: $++31 \quad 24$ 3540254; email: n.steinkamp@efg.kun.nl 